\title{
Heavy Metal Contamination in Green Leafy Vegetables Irrigated with Wastewater Collected from Harar Town Vegetable Farm, Ethiopia
}

\author{
Getachew Alamnie* Ameha Kebede Sissay Menkir \\ College of Natural and Computational Science, Haramaya University, \\ P.O.Box: 138, Dire Dawa, Ethiopia
}

\begin{abstract}
Food safety issues are of growing concern to consumers globally because of the risks associated with consumption of foods contaminated with heavy metals. In Harar town, Kebele 05 vegetable farm is known to produce vegetables irrigated with wastewater. To what extent these vegetables are contaminated with heavy metals was not known. Thus, a laboratory based cross sectional study was conducted from October 2016 to January 2017 to assess the extent of heavy metal contamination of vegetables. Accordingly, a total of 72 samples from four leafy vegetables namely lettuce (Lactuca sativa), spinach (Spinacea oleracea), kale (Brassica carinata)) and cabbage (Brassica oleracea) were determined. Lead $(\mathrm{Pb})$, Cadmium $(\mathrm{Cd})$, and Chromium $(\mathrm{Cr})$ concentration was determined using atomic absorption spectrophotometry. In all the vegetables, the mean concentrations of $\mathrm{Pb}, \mathrm{Cd}$ and $\mathrm{Cr}$ were 0.17 , 0.62 and $1.78 \mathrm{mg} / \mathrm{kg}$, respectively in all vegetables. Cd was found in level more than the maximum limit recommended by FAO/WHO but the level of lead was within the normal range for all vegetables. Chromium was found also within the normal range in all vegetables except in lettuce. The findings of this study have important information on the implications of public health by sequestration of heavy metals to these leafy vegetables then to among vegetable consumers of Harar town and the surroundings. Thus, it is recommended that the concerned public health authorities need to create awareness in the community and discouraging the use of untreated wastewater for cultivating vegetables.
\end{abstract}

Keywords: Contamination, Heavy metal, Vegetables, Wastewater

DOI: $10.7176 / \mathrm{FSQM} / 94-03$

Publication date: February $29^{\text {th }} 2020$

\section{INTRODUCTION}

Municipal wastewater for the irrigation of vegetables by marginal farmers is a common practice in urban and peri urban ecosystems of many countries (Chang et al., 2013). Continuous irrigation of agricultural farms with sewage and wastewater leads to contamination by pathogenic organisms, organic matter, oil, solids and heavy metals accumulation in the vegetables (Sharma et al., 2007).

The use of wastewater for irrigation has increased the contamination of the edible portions of vegetables by heavy metals, potentially causing health risks (Muchuweti et al., 2006). In view of the increasing vulnerability related to the consumption of vegetables due to heavy metal accumulation, it is of practical significance to assess the amount of heavy metal accumulation from soil into vegetables irrigated with wastewater (Chang et al., 2013). Due to the potential toxicity, persistent nature and cumulative behaviour of heavy metals in vegetables, there is an urgency to assess the food products to certify that the levels of such pollutants meet the approved international norms (Abraha et al., 2013). Some of the heavy metals such as Zink, Nickel and Copper acts as micro nutrients at lower concentrations; they may become toxic at higher concentrations. Consumption of heavy metal contaminated vegetables causes a series of health crisis (Chang et al., 2013; Abraha et al., 2013).

In the urban areas, the use of wastewater in agriculture is a century old practice that is receiving renewed attention with the increasing scarcity of fresh-water resources in many arid and semi-arid regions (Ackerson et al., 2012). Wastewater is being generated in the current study area from commercial centers and industry used for cultivating vegetables. Many farm households that are irrigating their farmlands with wastewater in this area are not aware of the risks or the potential harmful environmental consequences. Altogether, the situation will put the consumers at high risk of contracting diseases. The magnitude of microbial contaminants and the levels of toxic heavy metals in vegetables grown on wastewater irrigated farms are not known in the study area. Therefore, the aim of this study was to assess the load of some toxic heavy metals and microbial contaminants on some vegetables irrigated in kebele 05 (Gomen sefer) vegetable farm found in Harar town.

\section{MATERIALS AND METHODS}

\subsection{Description of the Study Area}

Harar town is the capital city of Harari People National Regional State and is located in eastern part of Ethiopia. Geographically, it is located at $9^{0} 18^{\prime} 43^{\prime}$ ' $\mathrm{N}$ latitude and $42^{0} 07^{\prime} 23^{\prime}$ ' $\mathrm{E}$ ' longitude. The elevation of the town is approximately between 1800 and 2200 meters above sea level (masl). Kebele 05 vegetable farm is found within 
Abadir woreda which is using water for irrigation from different sources including Harar beer brewery and domestic water; and its geographical position is suitable for getting the entire water source that drains from the surrounding villages. Major vegetables grown in this area include cabbage (Brassica oleracea), lettuce (Lactuca sativa), Spinach (Spinacea oleracea), and kale (Brassica carinata),

\subsection{Study Design and Sample Collection}

A laboratory based cross sectional survey was conducted from October 2016 - January 2017 to assess the microbial contaminants and level of heavy metals concentration on the main selected leafy vegetables [Lettuce (Lactuca sativa), Cabbage (Brassica oleracea), Spinach (Spinacea oleracea), and kale (Brassica carinata)] that are grown in Harar town, kebele 05 vegetable farm. The vegetable samples were analysed for concentrations of the heavy metals such as cadmium $(\mathrm{Cd})$, lead $(\mathrm{Pb})$, and chromium $(\mathrm{Cr})$ using Atomic Absorption Spectrophotometry (AAS). A random sampling procedure was adopted to collect the vegetable samples. A total of 72 samples comprising four vegetable types were collected from kebele 05 (Gomen Sefer) vegetable farm found in Harar town. All samples were collected aseptically in a disinfected universal ice box and transported to Haramaya University for microbiological and heavy metal analysis.

\subsection{Determination of Heavy Metals in Leafy Vegetable Samples 2.3.1. Instruments and Apparatus}

Ceramic pestle and mortar were used for grinding and homogenizing dried vegetable samples according to its type; digital analytical balance and dry heat oven were used for weighing and drying the samples, respectively. Flame atomic absorption spectrometry (Model 210/211 VGP, USA) equipped with deuterium background and hallow cathode lamp of each of metals was used to detect the absorbance of the metals $(\mathrm{Pb}, \mathrm{Cr}$ and $\mathrm{Cd})$ using air acetylene flame. Borosilicate volumetric flasks were used during dilution of samples and preparation of metal standard solutions. A refrigerator was used to store the samples which were digested till analysis. In addition funnels and whatman filter paper were used to filter the undissolved particles.

\subsubsection{Chemicals and Reagents}

All the chemicals that were used were, of high purity analytical grade. Distilled water was used for sample preparation, dilution and rinsing apparatus prior to analysis. Cadmium nitrate $\left(\mathrm{Cd}\left(\mathrm{NO}_{3}\right)_{2}\right)$, Lead nitrate $\left(\mathrm{Pb}\left(\mathrm{NO}_{3}\right)_{2}\right)$ and Potassium dichromate $\left(\mathrm{K}_{2} \mathrm{Cr}_{2} \mathrm{O}_{7}\right)$ were used to prepare standards; $70 \% \mathrm{HNO}_{3}, 30 \% \mathrm{H}_{2} \mathrm{O}_{2}$ and $38 \% \mathrm{HCl}$ were used for digestion of samples.

\subsubsection{Calibration Curve}

In this study, a calibration curve was constructed in order to determine the concentration of the experimental vegetable samples for lead, cadmium and chromium. Series of standard solutions were prepared using the stock solutions and diluted with distilled water to obtain five working standards for each metal ion of interest. In this study a total of three metals were analyzed using flame atomic absorption spectrophotometer. All the three metals $(\mathrm{Pb}, \mathrm{Cr}$ and $\mathrm{Cd})$ were analyzed by the absorption mode of the instrument. The concentrations and measured absorbance data for each set of standard metal ion solutions were used to construct the calibration curve then the unknown concentration of the vegetables were calculated using the equation from the standard calibration curve.

\subsubsection{Preparation of Vegetable Samples}

All samples were collected and stored in sterile ice box and brought to the laboratory for preparation. Then they were thoroughly mixed to give a composite sample as representative fraction of the vegetables. About $1 \mathrm{~kg}$ of the edible portions (leaves) of these vegetables [(Cabbage (Brassica oleracea), Lettuce (Lactuca sativa), Spinach (Spinacea oleracea) and kale (Brassica carinata)] was prepared for heavy metal (lead, chromium and cadmium) determination. The bruised or rotten portions were removed. In the laboratory, collected vegetable samples were washed with tap water and then with double distilled water to eliminate adsorbed dust and particulate matters. Samples were then cut and chopped into small pieces using scissor in order to facilitate drying. The samples then air dried for five to six days and further dried in a hot air oven at $50-60{ }^{\circ} \mathrm{C}$ for $24 \mathrm{hr}$ to remove moisture and maintain constant mass and at the end of drying, the oven was turned off and left over night to enable the sample cool to room temperature (Adugna et al., 2015). Finally, the dried samples were ground into powder using acidwashed mortar and pestle.

\subsubsection{Digestion of Vegetable Samples}

A mixture of $0.5 \mathrm{~g}$ of homogenized powdered vegetable samples and $10 \mathrm{ml}$ of $\mathrm{HNO}_{3}-\mathrm{HCl}_{-}-\mathrm{H}_{2} \mathrm{O}_{2}(8: 1: 1$, v/v/v) were added into a borosilicate flask. The mixture was heated at $120^{\circ} \mathrm{C}$ over $3 \mathrm{~h}$ on a hot plate. After the completion of the digestion, the bright yellowish solutions were transferred into $50 \mathrm{ml}$ of volumetric flak. Each digestion tube was rinsed with distilled water to collect any possible residue, and added to the volumetric flask which made up to volume with distilled water. Then dilute samples were stored in $100 \mathrm{ml}$ plastic bottles until analysis. Each vegetable sample was digested and analysed in triplicate to increase the precision of the result. The blank solution was prepared by taking a mixture of $8 \mathrm{ml} \mathrm{HNO}_{3}, 1 \mathrm{ml} \mathrm{HCl}$ and $1 \mathrm{ml} \mathrm{H}_{2} \mathrm{O}_{2}$ and treating similarly as that of the samples (Tadele et al., 2015). Then the heavy metals ( $\mathrm{Cr}, \mathrm{Pb}$, and $\mathrm{Cd}$ ) were analysed by atomic absorption 
spectrophotometry. All concentrations of metals were expressed in $\mathrm{mg} / \mathrm{kg}$ of dry weight.

\subsection{Data Analysis}

In this study, all statistical analyses were computed using SPSS software version 20 for heavy metal analysis. Microsoft Excel was used to draw calibration curves and graphs. As the level of heavy metal contamination might vary with vegetable types, ANOVA was used to test the existence of significant difference between means. In statistical analyses, confidence level was held at at $99 \%$ and $\mathrm{P}<0.01$ (at $1 \%$ level of significance) were considered as significant.

\section{RESULTS AND DISCUSSION}

\subsection{Heavy Metal Determination in Vegetables}

The concentrations of lead, cadmium and chromium in vegetables (leaf) were determined (Table 1). The concentrations of Lead, Chromium and Cadmium in leafy vegetable samples ranged from 0.04 to $0.3 \mathrm{mg} / \mathrm{kg}, 0.7$ to $3.2 \mathrm{mg} / \mathrm{kg}$, and 0.3 to $1.0 \mathrm{mg} / \mathrm{kg}$, respectively, with mean concentrations of $0.17,1.78$ and $0.62 \mathrm{mg} / \mathrm{kg}$, respectively.

Table 1: Mean concentration of three purposively selected heavy metals in leafy vegetables cultivated at Harar town vegetable farm in terms of $\mathrm{mg} / \mathrm{kg}$ dry weight $($ Mean $\pm \mathrm{SE})$

\begin{tabular}{llll}
\hline & \multicolumn{2}{l}{ Detected heavy metals } & \\
\cline { 2 - 4 } Leafy vegetables & Lead $(\mathrm{Pb})$ & Chromium $(\mathrm{Cr})$ & Cadmium $(\mathrm{Cd})$ \\
\cline { 2 - 4 } & & & \\
Lettuce & $0.27 \pm 0.03^{\mathrm{a}}$ & $2.60 \pm 0.3^{\mathrm{a}}$ & $0.50 \pm 0.06^{\mathrm{bc}}$ \\
Spinach & $0.06 \pm 0.01^{\mathrm{b}}$ & $2.23 \pm 0.03^{\mathrm{ab}}$ & $0.37 \pm 0.03^{\mathrm{c}}$ \\
Kale & $0.13 \pm 0.03^{\mathrm{ab}}$ & $0.77 \pm 0.03^{\mathrm{c}}$ & $0.67 \pm 0.07^{\mathrm{b}}$ \\
Cabbage & $0.23 \pm 0.03^{\mathrm{a}}$ & $1.53 \pm 0.03^{\mathrm{b}}$ & $0.93 \pm 0.03^{\mathrm{a}}$ \\
For all vegetables & $0.17 \pm 0.03$ & $1.78 \pm 0.2$ & $0.62 \pm 0.07$ \\
\hline Maximum limit & $0.3^{* * *}$ & $2.3^{* * *}$ & $0.2^{* * *}$ \\
\hline
\end{tabular}

$\mathrm{SE}=$ standard Error of the mean

a-b-c Means with different superscript letters down the column for the same parameter with in vegetable types do significantly differ $(\mathrm{P}<0.01)$

Kale (Yegurage gomen)

$* * *$ Source: FAO/WHO (2011)

Vegetable species differ in their ability to take up and accumulate heavy metals, even among varieties within the same species (Säumel et al., 2012). A study conducted by, Muchuweti et al. (2006) who reported that vegetables grown on land amended with sewage sludge presented a health risk for humans, in Zimbabwe. In addition, Adekunle et al. (2009) found that $\mathrm{Pb}$ concentration in leafy vegetables exceeded recommended values for three cities in Nigeria.

\subsubsection{Lead}

The mean concentrations of $\mathrm{Pb}$ were $0.27 \mathrm{mg} / \mathrm{kg}, 0.06 \mathrm{mg} / \mathrm{kg}, 0.13 \mathrm{mg} / \mathrm{kg}$ and $0.23 \mathrm{mg} / \mathrm{kg}$ in lettuce, spinach, $\mathrm{kale}$ and cabbage, respectively. The mean value of $\mathrm{Pb}$ reported in this study $(0.17 \pm 0.03 \mathrm{mg} / \mathrm{kg})$ for all vegetable samples was lower than the data obtained by, Sharma et al. (2006) who reported that the $\mathrm{Pb}$ concentration in leafy vegetables grown in industrial areas of Varanasi (India) was $17.54-25.00 \mathrm{mg} / \mathrm{kg}$.

In addition, Muchuweti et al. (2006) reported that the level of $\mathrm{Pb}$ in vegetables irrigated with wastewater from Zimbabwe was $6.77 \mathrm{mg} / \mathrm{kg}$. The highest mean value of $\mathrm{Pb}$ in the present study was in lettuce $(0.27 \mathrm{mg} / \mathrm{kg})$ and the lowest mean was in kale, but all vegetables were below the maximum limit $(0.3 \mathrm{mg} / \mathrm{kg})$ recommended by FAO/WHO (2011). In contrast to this study, Kumar et al. (2009) and Farooq et al. (2008) who reported that Pb concentration was above limited level in leafy vegetables grown in vicinity of an industrial area of Jaipur city (India) and Faisalabad (Pakistan), respectively.

The present result showed that the level of $\mathrm{Pb}$ ranged between 0.04 to 0.3 in all vegetables, and 0.2 to 0.3 $\mathrm{mg} / \mathrm{kg}$ for lettuce, 0.04 to $0.07 \mathrm{mg} / \mathrm{kg}$ for spinach, 0.1 to $0.2 \mathrm{mg} / \mathrm{kg}$ for kale (yegurage gomen) and 0.2 to $0.3 \mathrm{mg} / \mathrm{kg}$ for cabbage. A study conducted by Kumar et al. (2009) who reported that the concentration of lead in lettuce ranged from 2.3 to $5.3 \mathrm{mg} / \mathrm{kg}$ which is greater than the present result $(0.2$ to $0.3 \mathrm{mg} / \mathrm{kg})$. Study conducted by, Yirgaalem et al. (2012) who reported that $\mathrm{Pb}$ levels in vegetables varying from 0.11 to $0.89 \mathrm{mg} / \mathrm{kg}$ which was greater than the present result.

\subsubsection{Cadmium}

The mean concentration of cadmium $(\mathrm{Cd})$ in lettuce, spinach, kale and cabbage was $0.50,0.37,0.67$, and 0.93 $\mathrm{mg} / \mathrm{kg}$, respectively. The concentration of $\mathrm{Cd}$ was significantly difference amongst vegetable types. In all the vegetable samples analyzed, cadmium concentration ranged between 0.30 to $1.00 \mathrm{mg} / \mathrm{kg}$. In contrast, Odai et al . (2008) reported that the concentration of cadmium in vegetables grown on waste dumping sites was $0.68-1.78$ $\mathrm{mg} / \mathrm{kg}$ in Kumasi (Ghana). The accumulation of elevated concentration of $\mathrm{Cd}$ in all vegetables might be attributed 
to the use of water from contaminated source for cultivation. All vegetable types contained cadmium concentration levels were exceeded the recommended maximum value for leafy vegetables of $0.2 \mathrm{mg} / \mathrm{kg}$.

Similarly, Levels exceeding the maximum limit of leafy vegetables were reported for cadmium in studies conducted by Sharma et al. (2007), Yirgaalem et al., (2012) and Farooq et al. (2008), in Harare (Zimbabwe), Addis Ababa (Ethiopia) and Faisalabad (Pakistan), respectively. This may be because of cadmium is easily absorbed and translocate to shoots of vegetables (Mumba et al., 2008).

\subsubsection{Chromium}

In this study the chromium concentration ranged from $0.7-3.2 \mathrm{mg} / \mathrm{kg}$ for all vegetables. This shows that chromium levels are generally within normal range almost in all vegetable samples, except lettuce $(2.60 \mathrm{mg} / \mathrm{kg})$ as shown in Table 1. Similar with this result, Fisseha (1998) reported that the concentration of $\mathrm{Cr}$ was highest in lettuce at Peacock vegetable farm Addis Ababa (Ethiopia). In addition, Sharma et al. (2006) demonstrated that the heavy metal contents in different vegetables grown in the lands irrigated by wastewater and noted the concentration of $\mathrm{Cr}$ to be within the safe limits. In line with the present finding, Farooq et al. (2008) reported that $\mathrm{Cr}$ was within the permitted limits in leafy vegetables grown in vicinity of an industrial area of Faisalabad (Pakistan).

\section{Conclusion}

Wastewater irrigation can also lead to accumulation of heavy metals in the soil and consequently into the vegetables, exposing the human population of the area and surrounding community to serious health risks. It may be concluded that irrigation by untreated sewage water and industrial effluents are the main reasons for accumulation of heavy metals in vegetables. Generally, the results of the present study revealed that heavy metal and microbial contamination of vegetables in varying magnitude among vegetables in the study area which may lead to public health crisis.

\section{Acknowledgement}

The authors thank to Haramaya University college of Natural and Computational Sciences and department of Biological Sciences and biotechnology for the financial, material support and laboratory materials provision.

\section{REFERENCES}

Abraha Gebrekidan, Yirgalem Woldegebriel, Amanual Hadera, Bruggen, B.V. 2013. Toxicological assessment of heavy metals accumulated in vegetables and fruits grown in Ginfel River near Sheba Tannery, Tigray, and Northern Ethiopia. Ecotoxicology and Environmental Safety, 95:171-178.

Ackerson, N.O.B. and Awuah, E. 2012. Microbial risk assessment of urban agricultural farming: A case study on Kwame Nkrumah University of Science and Technology campus, Kumasi, Ghana. International Journal of Engineering and Technology, 2(3): 356-363.

Adekunle, I.M., Olorundare, O., Nwange, C. 2009. Assessments of lead levels and daily intakes from green leafy vegetables of southwest Nigeria. Nutrition and Food Science, 39:413-422.

Adugna Boke, Negussie Megersa and Endale Teju. 2015. Quantitative Determination of the Heavy Metal Levels in the Wild Edible Plant Parts and their Corresponding Soils of the Central and Western Regions of the Oromia State, Ethiopia. Journal of Environmental and Analytical Toxicology, 5(5):299-307.

Chang, C.Y., Yu, H.Y., Chen, J.J., Li, F.B., Zhang, H.H., Liu, C.P. 2013. Accumulation of heavy metals in leaf vegetables from agricultural soils and associated potential health risks in the Pearl River Delta. Environmental Monitoring and Assessment, South China. Doi: 10.1007/s10661- 013-3472-0.

FAO/WHO (Food and Agricultural Organisations of the United Nations/World Health Organisation). 2011. Joint FAO/WHO food standards programme codex committee on contaminants in foods fifth session. The Hague, Netherland, 21 - 25 March 2011.

Farooq, M., Anwar, F. and Rashid, U. 2008. Appraisal of Heavy metals grown in the vicinity of an industrial area. Pakistan Journal of Botany, 40: 2099-2106.

Fisseha Ittana. 1998. Metal concentrations of some vegetables irrigated with industrial liquid waste at Akaki, Ethiopia. Ethiopian Journal of Science, 21(1): 133- 144.

Kumar, A., Sharma, I.K., Sharma, A., Varshneg, S., and Verma. P.S. 2009. Heavy metal contamination of vegetable foodstuffs in Jaipur (India). Electronic Journal of Environmental, Agricultural and Food Chemistry, $8(2): 96-101$

Muchuweti, M., J.W. Birkett, E. Chinyanga, R. Zvauya, M.D. Scrimshaw and J.N. Lester. 2006. Heavy metal content of vegetables irrigated with mixture of waste water and sewage sludge in Zimbabwe: implications for human health. Agriculture, Ecosystem and Environment, 112: 41-48.

Mumba, P.P., Chibambo, B.Q. and Kadewa, W. 2008. A comparison of the levels of heavy metals in cabbages irrigated with reservoir and tap water. International Journal of Environmental Research, 2(1): 61-64.

Odai, S.N., Mensah, E., Sipitey, D. Ryo, S. and Awuah, E. 2008. Heavy metals uptake by vegetables cultivated on urban waste dumpsites: Case study of Kumasi, Ghana. Res. Journal of Environmental Toxicology, 2: 92-99. 
Säumel, I., Kotsyuk, I., Hölscher, M., Lenkereit, C., Weber, F., Kowarik, I. 2012. How healthy is urban horticulture in high traffic areas? Trace metal concentrations in vegetable crops from plantings within inner city neighbour hoods in Berlin,

Sharma, R.K., Agrawal, M., Marshall, F. 2006. Heavy metals contamination in vegetables grown in wastewater irrigated areas of Varanasi, India. Bulletin of Environmental Contamination and Toxicology, 77:312-318.

Sharma, R.K., Agrawal, M., Marshall, F.M. 2007. Heavy metals contamination of soil and vegetables in suburban areas of Varanasi, India. Ecotoxicology and Environmental Safety, 66:258-266.

Tadele Atinafu, Taddese Mekonnen, and Somasundaram, J. 2015. Determination of some toxic heavy metal accumulation in medicinal plants commonly used in Gondar area district, North-western Ethiopia. International Journal of Pharmacy and Analytical Research, 4(4): 399-405.

Yirgaalem Woldegebriel, Bhagwan Singh Chandravanshi, Tadesse Wondimu. 2012. Concentration levels of metals in vegetables grown in soils irrigated with river water in Addis Ababa, Ethiopia. Ecotoxicology and Environmental Safety, 77: 57-63. 